\title{
A perspective on the measurement of time in plant disease epidemiology
}

\author{
D. J. Lovell ${ }^{a \star} \dagger$, S. J. Powers ${ }^{a}$, S. J. Welham ${ }^{a}$ and S. R. Parker ${ }^{b}$ \\ ${ }^{a}$ Rothamsted Research, Harpenden, Herts AL5 2JQ; and ${ }^{b}$ Central Science Laboratory, Sand Hutton, York YO41 1LZ, UK
}

The growth and development of plant pathogens and their hosts generally respond strongly to the temperature of their environment. However, most studies of plant pathology record pathogen/host measurements against physical time (e.g. hours or days) rather than thermal time (e.g. degree-days or degree-hours). This confounds the comparison of epidemiological measurements across experiments and limits the value of the scientific literature.

Keywords: degree-days, epidemic rate, thermal time

\section{Introduction}

In 1735 Réaumur suggested that the biological development of an organism proceeds only when a certain number of 'heat units' have been accumulated. The general veracity of that observation has been demonstrated for many biological processes in the intervening years. For example, it has been used to determine rates of colonization, growth and maturation for many insect species and microorganisms. Researchers in entomology and plant physiology usually measure growth and development against thermal time, which is an accumulation of heat units above some threshold (base) temperature over a specified period of time, usually 24 h. Réaumur (1735) first put forward the idea of a base temperature, and Bonhomme (2000) reviewed the use of degree-days in particular, including their application to plant development.

Thermal time is known to be important in assessment and modelling of growth and development of many plant pathogens, for example Mycosphaerella graminicola, anamorph Septoria tritici (leaf blotch) and Gaeumannomyces graminis (take-all) in wheat (Brasset \& Gilligan, 1989; Schoeny \& Lucas, 1999; Lovell et al., 2004); Verticillium dahliae (verticillium wilt) in potato (Mol et al., 1996); and Xanthomonas campestris pv. dieffenbachiae (bacterial blight) in anthurium (Fukui et al., 1999). Models, which may incorporate quite complex functions of temperature, can be used successfully to predict the

*To whom correspondence should be addressed.

†E-mail: Darren.Lovell@bbsrc.ac.uk

Accepted 28 June 2004 onset and extent of disease, for example in the cases of Podosphaera leucotricha (powdery mildew) in apple shoots (Xu, 1999a); Puccinia graminis ssp. graminicola (stem rust) in perennial ryegrass (Pfender, 2003); and Sclerotinia sclerotiorium in lettuce (Clarkson et al., 2004).

In the field of horticulture, Wurr et al. (2002) provide a review that considers the importance and applicability of thermal time to crop scheduling and prediction of crop maturity in particular, an area of research where the concept appears to be generally acknowledged and used where appropriate. Most studies of plant pathology, however, use physical time scales (hours or days), even when there is evidence to suggest that thermal time may be a more appropriate measure. It is not immediately clear why plant pathologists have failed to embrace the concept of thermal time as a standard scale. For most investigations, whether field- or laboratory-based, the collection of appropriate temperature data is a relatively trivial task, which suggests that it is either deliberately not collected, or is unused during data analysis. Certainly, it is implausible that plant pathologists are unfamiliar with the concept of thermal time. Lack of uptake could therefore be caused by the absence of standard frameworks to analyse the sometimes complex nature of the temperature-organism relationship, and this might explain why there is a tendency for greater use and application of thermal time in studies that involve both mathematical modellers and plant pathologists.

This letter seeks to demonstrate and discuss the benefits for plant pathology of measuring growth and development against thermal time. These benefits are considered in relation to individual studies, and also more widely, in terms of how they might increase the value of observations 
reported in scientific literature by facilitating more meaningful comparisons of epidemiological measurements across studies.

\section{Variation in temperature over time}

Good scientific practice demands that experimental designs should provide a means of controlling, or accounting for, the environmental variables likely to affect the system. This is especially important when an experiment is replicated across more than one occasion. For pathosystems, the prevailing environment can influence both the defence put up by the plant and the attack made by the pathogen. This is exemplified by the role of temperature (affecting phyllochron, infection and latent period) and rainsplash (affecting spore dispersal) shown for S. tritici in wheat (Lovell et al., 1997, 2004). If temperature is known or expected to influence the development and growth of a particular system, it is logical, in the simplest case, to provide an estimate of the base temperature (below which growth in the system ceases and hence at which accumulation of thermal time should stop), and to use the linear thermal time scale that is derived as a basis for measurements. Otherwise, epidemiological parameters (e.g. rates of development) and measurements (e.g. area under the disease-progress curve, AUDPC) expressed in terms of physical time are likely to be grossly misleading. This problem will be especially acute when comparisons are made across experiments that have experienced variable temperatures typical, for example, of field conditions.

To demonstrate this point further, 25 years of mean daily temperature data (1975-99), collected at Long Ashton Research Station (LARS), Bristol, UK, were examined. The running 7-day maximum, minimum and mean thermal time accumulations over years, taking a base temperature of $0^{\circ} \mathrm{C}$, are shown in Fig. 1 . As a result of seasonal variation, thermal time accumulation is not consistent over a 12 month period. Therefore the longer an experiment runs, the worse the estimation of rates of development in terms of time will be for a system

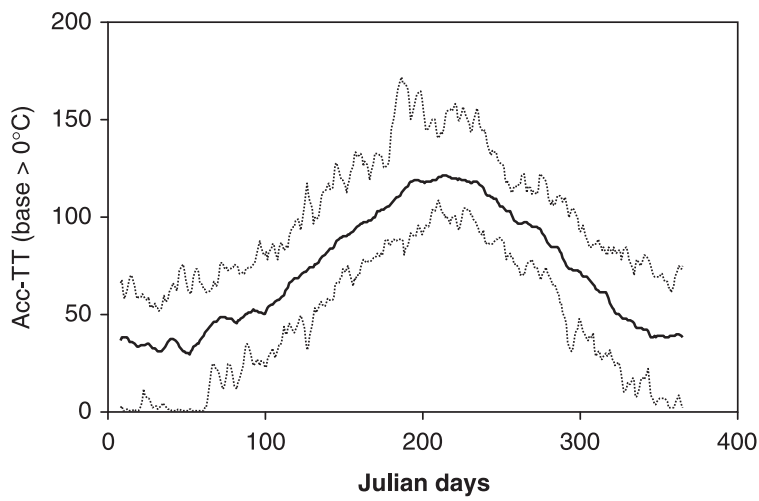

Figure 1 Mean running 7-day thermal time accumulation (Acc-TT; base temperature $=0^{\circ} \mathrm{C}$ ) for Long Ashton Research Station (LARS), UK 1976-99. Solid line, mean values; dashed lines, variation between years (maximum and minimum values for the 25-year period).

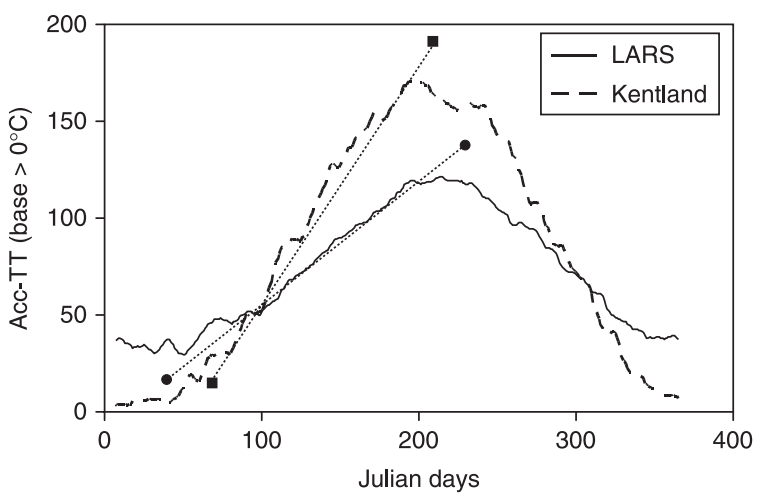

Figure 2 Mean running 7-day thermal time accumulations (Acc-TT) over 25 years for two locations: LARS, UK and Kentland, IN, USA. Mean rate of change in accumulation over a 100-day period from 1 April was approximately 1.2 units per day at Kentland (dashed line), compared with 0.7 at LARS (solid line).

responding to temperature. This can be demonstrated by considering a simple example. Suppose that a measure of disease severity, $y$, expressed as a percentage, is dependent on thermal time, $T$, and follows a logistic pattern of increase with an exponential rate of 0.03 and an initial infection level (at $T=0$ ) of $1 \%$, so that

$$
y=100 /\left(1+99 e^{-0.03 \mathrm{~T}}\right)
$$

For LARS, the mean rate of change in weekly accumulation of thermal time, for a period across the summer months, can be estimated assuming a linear trend (Fig. 2). For the period of 100 days from 1 April (the main period of rapid growth and yield formation of many UK crops), this equates to approximately 0.7 thermal time units per day. Using this rate of temperature accumulation in association with Eqn 1 for the disease, and selecting three possible starting points for the same experiment as day 0 (1 April), day 35 and day 70 (Table 1), three separate logistic patterns of disease increase in terms of days can be seen (Fig. 3a). For this expression of disease progress, the exponential rate of growth increases with delay in the start of the experiment. Similarly, modelling the data transformed as $r=\log [y /(100-y)]$, as for a polycyclic disease (Vanderplank, 1963), and using a daily scale, separate rates of increase are estimated as $0 \cdot 26,0.35$ and 0.44 for the three starting dates of 0,35 and 70 , respectively (Fig. 3b). If, however, calculations are made on the thermal time scale, the rate of increase in $r$ is identical $(0 \cdot 013)$, regardless of starting date. This simulated example is analogous to, and supported by, data from Lovell et al. (2004), who accounted for seasonal and annual variation in temperatures to estimate the latent period of $S$. tritici from measurements taken in a long-term outdoor study. On the thermal time scale the rates of increase in disease expression at different times of the year were seen to be much the same, whereas on a daily scale the rates were clearly dependent on the time of year, thus making estimation of a latent period impractical on that scale. 
(a)

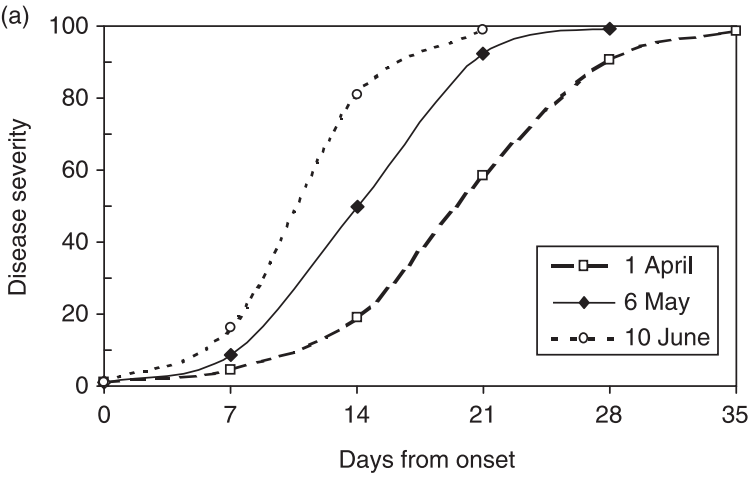

(b)

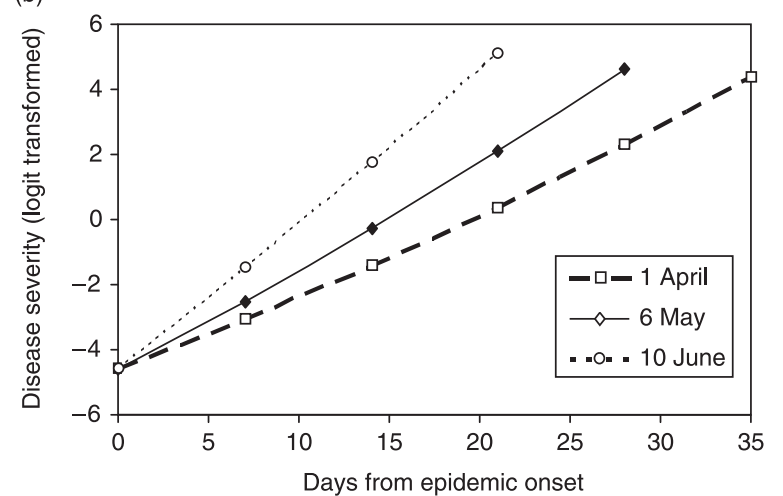

Figure 3 (a) Simulated disease-progress curves for an epidemic, where growth rate is fixed with respect to thermal time accumulation starting on three dates (1 April, 6 May and 10 June) and where the thermal time data used are the mean running 7 -day values for LARS (1975-99). (b) Simulations as in (a) but with data transformed as $r=\log [y /(100-y)]$ as for a polycyclic disease (Vanderplank, 1963) and using a daily scale from epidemic onset. Separate rates of increase are estimated as 0.26, 0.35 and 0.44 for epidemics starting on 1 April, 6 May and 10 June, respectively.
For polycyclic pathogens, observations of epidemic development are often made over long durations. Hence, where temperature is generally increasing over the cropping season, disease progress will tend to appear exponential if viewed on physical time scales. When considered on a thermal time scale, however, these progress curves often assume a linear or even logistic trend. An example of this is shown in Fig. 4 for the cumulative progress of an epidemic of leaf blotch on barley, caused by Rhynchosporium secalis (reproduced from Davies, 1990). This example also shows the effect of seasonal variation in temperature through the comparison of epidemics on autumn- and spring-sown crops. When viewed in physical time (Fig. 4a), the early rate of epidemic development for the spring-sown crop appears more rapid than that of the autumn sowing. However, when considered against thermal time (Fig. 4b), there is very little difference between the two epidemics.

\section{Variation in rate of temperature accumulation between locations}

Comparing the temperature data for LARS with similar data from a meteorological station in Kentland, IN, USA shows that the influence of annual variations in temperature are not consistent across geographically distinct locations (Fig. 2). For example, the rate of change in thermal time accumulation over the 100-day period from 1 April at Indiana was approximately 1.2 units per day, compared with 0.7 for LARS. This demonstrates how local climate determines the relevant importance of using thermal time for a given site. Where there is a more rapidly changing seasonality in temperature, or where annual variation across years is greater, the extent of misinterpretation of biological processes with respect to days is likely to be greater.

The importance of accounting for geographic variation in temperature was demonstrated by Parker \& Lovell (2001). Comparing the results of two experiments, they

Table 1 Simulated data set to compare disease progress in terms of time (days) and thermal time (degree-days)

\begin{tabular}{|c|c|c|c|c|c|c|c|c|}
\hline $\begin{array}{l}\text { Time } \\
\text { (days) }\end{array}$ & $\begin{array}{l}\text { Weekly thermal } \\
\text { time (degree-days) }\end{array}$ & $\begin{array}{l}\text { Accumulated } \\
\text { thermal time }\end{array}$ & $\begin{array}{l}\text { Time } \\
\text { (days) }\end{array}$ & $\begin{array}{l}\text { Disease } \\
\text { expression } \\
(\%)\end{array}$ & $\begin{array}{l}\text { Time } \\
\text { (days) }\end{array}$ & $\begin{array}{l}\text { Disease } \\
\text { expression } \\
(\%)\end{array}$ & $\begin{array}{l}\text { Time } \\
\text { (days) }\end{array}$ & $\begin{array}{l}\text { Disease } \\
\text { expression } \\
(\%)\end{array}$ \\
\hline 0 & 0 & 0 & 0 & 0 & & & & \\
\hline 7 & $50 \cdot 00$ & $50 \cdot 00$ & 7 & 20 & & & & \\
\hline 14 & $54 \cdot 82$ & $104 \cdot 82$ & 14 & 41.92 & & & & \\
\hline 21 & $59 \cdot 65$ & $164 \cdot 47$ & 21 & $65 \cdot 79$ & & & & \\
\hline 28 & $64 \cdot 47$ & 228.94 & 28 & 91.58 & 0 & 0 & & \\
\hline 35 & $69 \cdot 29$ & $298 \cdot 23$ & & & 7 & $27 \cdot 72$ & & \\
\hline 42 & $74 \cdot 12$ & 372.35 & & & 14 & $57 \cdot 36$ & & \\
\hline 49 & 78.94 & $451 \cdot 28$ & & & 21 & 88.94 & & \\
\hline 56 & $83 \cdot 76$ & 535.04 & & & & & & \\
\hline 63 & 88.58 & 623.63 & & & & & & \\
\hline 70 & 93.41 & $717 \cdot 04$ & & & & & & \\
\hline 77 & 98.23 & $815 \cdot 27$ & & & & & 0 & 0 \\
\hline 84 & 103.05 & $918 \cdot 32$ & & & & & 7 & $41 \cdot 22$ \\
\hline 91 & $107 \cdot 88$ & $1026 \cdot 19$ & & & & & 14 & 84.37 \\
\hline
\end{tabular}



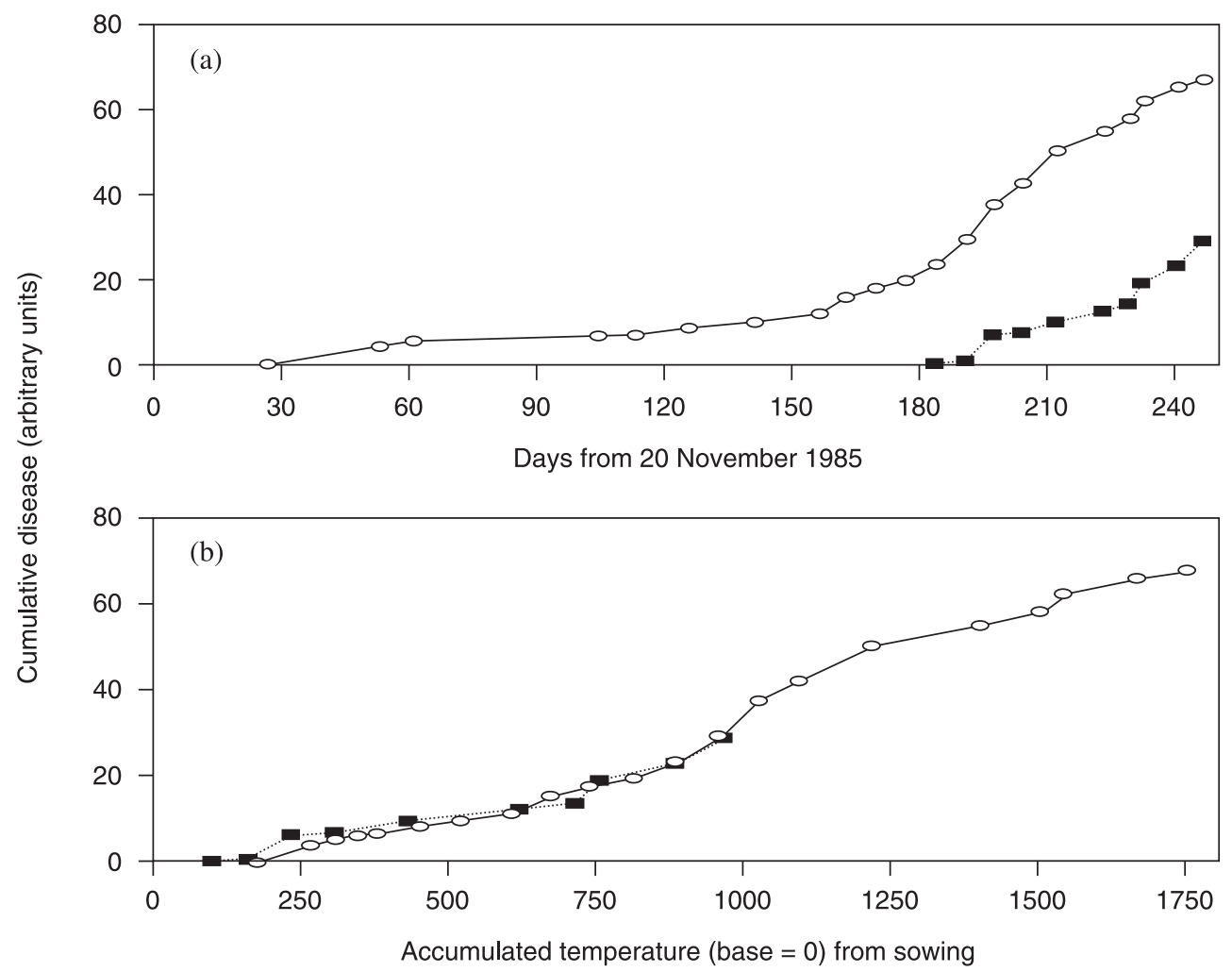

Figure 4 Progress of epidemics of leaf blotch, Rhynchosporium secalis, on barley for winter- $(\bigcirc)$ and spring-sown $(\mathbf{\square})$ crops, plotted with respect to (a) physical time (days) and (b) physiological time (degree-days). Data reproduced from Davies (1990).

found that spore production of $S$. tritici was very similar for crops sown on the same date in two geographic regions within the UK (LARS, south-west and High Mowthorpe, north-east). This similarity was made evident only by measuring progress according to the accumulation of thermal time, for which there was a large difference between the sites. Extending this study to consider crops sown at the same locations but with different sowing dates showed that a considerable proportion of the differences in spore production observed between crops could also be attributed to accumulated thermal time (D.J.L. and S.R.P., unpublished). These observations add credence to empirical correlations reported between winter temperatures and summer observations of S. tritici epidemics (Gladders et al., 2001; Pietravalle et al., 2003).

Further relevance of thermal time in the context of comparing locations is provided when considering the effects that locally adapted populations or known different genetic strains of pathogens may have. These effects may include differences in the rate of development in response to temperature or variation in the base temperature.

\section{Statistical analysis}

Modelling data from experiments that consider pathogen response to temperature allows the form (linear, piecewise linear or nonlinear) of the rate of disease development to be defined in terms of this environmental variable. The form can be investigated most easily by modelling data from experimentation across a range of constant temperatures, but the relationship obtained in this case may not be the same as that in the situation of fluctuating temperature in the field. However, when modelling data from the field, an underlying assumption about the form of the response to temperature is required and the modelling allows this assumption to be tested only in terms of the range of temperatures experienced. Together, both methods of experimentation can successfully define the form of the pathogen response to temperature, and proposed models can then be validated by collecting data under different sets of temperature conditions to verify model predictions of thermal times to events.

When the rate of development in the system is assumed to be linear with increasing temperature, a base temperature should be chosen that provides the minimum coefficient of variation of the temperature accumulations (Arnold, 1959); however, base temperatures are often fixed at $0^{\circ} \mathrm{C}$ without justification. Where a base temperature other than $0^{\circ} \mathrm{C}$ is used, it is often derived from previous studies that estimated the lower limit for biological activities such as infection or sporulation (Tyldesley, 1978). For example, Scherm et al. (2001) used $7 \cdot 2^{\circ} \mathrm{C}$ as a base temperature in a study of germination of pseudosclerotia of Monilinia vaccinii-corymbosi (mummy berry disease) in blueberry, citing Milholland (1977). 
Where the base temperature is unknown, it can be estimated as the intercept of the regression of development rate (inverse of time to reach an ontogenetic phase) against average daily temperature (Olivier \& Annandale, 1998; Baker \& Reddy, 2001). However, a more thorough derivation of base temperature may be provided by modelling continuously recorded temperature and experimental data together. This second approach has been used, for example, in studies of plant growth (Aikman \& Scaife, 1993), seed germination (Grundy et al., 2000), cell proliferation (Powers et al., 2003) and pathogen development (Lovell et al., 2004). In the last of these cases, the benefit of estimating rather than assuming a base temperature was made evident by comparing disease-progress curves for different times of the year using a base temperature fixed at $0^{\circ} \mathrm{C}$ with those using an estimated value of $-2 \cdot 37^{\circ} \mathrm{C}$. With the estimated base temperature, the fit of the model used was better and the differences between batches of plants (representing seasonal differences over 2 years) were visibly reduced, thus more closely defining and confirming the temperature-driven nature of the disease.

Assumption of a linear response to temperature may often be inappropriate. As an alternative, a piecewise linear (Tyldesley, 1978), logistic or skewed bell-shaped curve could be more appropriate (Sharpe \& DeMichele, 1977). For example, the responses of cassava and maize crop growth to temperature were best described using a skewed probability density (beta) function (Yin et al., 1995). Observations of a nonlinear response to temperature, however, are often insufficiently detailed to allow estimation of all the parameters of putative nonlinear models. For example, if there are very few observations of temperature at the extremes of the potential range during the experimental period, it is unlikely that base, maximum and optimum temperatures for a proposed bell-shaped curve will be estimable. In such cases the linear approximation will be a reasonable alternative if, at least, a base temperature can be estimated (or imposed from existing knowledge), and if it is justifiable to assume the system has not experienced temperatures beyond the point where the optimum has been reached.

\section{Sampling period}

\section{Observation of temperature}

In its simplest form, and often in the absence of recorded temperature on a more frequent scale, accumulated thermal time is the sum of degree-days where each day is calculated as the average of the daily maximum and minimum temperatures adjusted for the base temperature when it is exceeded:

$$
[(\operatorname{maxtemp}+\operatorname{mintemp}) / 2]-\text { basetemp }
$$

While this method of calculation provides a good approximation, it may be unsuitable in some circumstances, for example where temperatures exceed the optimum temperature during part of the day, as mentioned above, or where a nonsymmetrical diurnal variation exists. Improvements to this method of calculation therefore use information on day length to adjust for the lack of symmetry of the diurnal cycle, for example Parton \& Logan (1981) or Reader \& Phelps (1991) who, in the context of the HEATUNITS directive in the GENSTAT statistical package (GenStat, 2003), incorporate the methods of Reicosky et al. (1989) to calculate units of development with respect to the proposed form of diurnal variation in temperature, given the consecutive daily maximum and minimum and the global latitude at which measurement is taken. Although such models can increase the accuracy of the thermal time calculation in the case where only maximum and minimum temperatures are available, improvement can be achieved simply by using frequent temperature measurements throughout each day, allowing calculation at the scale of degree-hours or degree-minutes. Generally, for models that include estimation of a base temperature, the use of concurrent hourly temperature data is preferable to using mean daily temperatures calculated from the hourly data prior to modelling. However, the frequency of temperature measurement, and hence the period of integration, need to be determined on a system-specific basis by considering the extent and rate of temperature fluctuation and the rate of change/development of the biological process under examination. Also, one would expect the frequency of measurement required to be less for controlled environments than in the field, where solar radiation, photoperiod, wind and evaporation are additional effects on temperature as well as on development per se. When modelling tree cell proliferation using data from hybrid aspen trees (Populus tremula $\times$ Populus tremuloides) experiencing the fluctuating temperatures of a glasshouse without supplementary heating and lighting, Powers et al. (2003) used temperature recorded every $3 \mathrm{~min}$ to estimate base temperatures and corresponding rates of cell production. They subsequently found that observation every $15 \mathrm{~min}$ provided a fit of the model with no less precision, but that taking observations more than $30 \mathrm{~min}$ apart led to a fit of poorer quality. In contrast, when modelling crop development, Purcell (2003) compared daily and hourly temperatures and found only a small loss in precision in estimating time to accumulation of 200 degree-days, except when average temperatures were above $34^{\circ} \mathrm{C}$ or close to the base temperature. When temperature is fluctuating, as in the case of field experiments, the need for frequent observations is likely to be greatest when systems are examined at the micro (cellular) level, rather than at the macro (ontogenetic) level. Despite this, the rate of change of temperature with time is also important, as there would be little advantage in moving from, for example, 10- to 5-min intervals between observations if temperature were already seen not to change perceptibly in the space of 10-min intervals.

Where conditioning or environmental variables secondary to temperature, but nevertheless vital to pathogen development, need to be considered - such as leaf wetness (Pfender, 2003) or humidity (Rowe \& Powelson, 1973) the measurement of environmental variables needs to be 
very frequent, otherwise important changes in the environment will be poorly detected or missed altogether.

\section{Observation of the system (epidemic)}

In order to design an appropriate sampling scheme for an epidemic, the rate of change of the epidemic needs to be considered (as mentioned above). For systems that are highly influenced by temperature, the expected or proposed base temperature and rate of system response to temperature should determine the start and frequency of system observation. Although there may be constraints imposed by experimental, economic and analytical requirements, the frequency of observations should, as far as possible, be directly related to thermal time accumulation rather than physical time. For example, if it is known from previous studies how many degree-days need to be accumulated from infection until lesion appearance, then observations should be made frequently around the thermal time at which first lesion appearance is expected, and then at regular degree-day intervals thereafter to chart disease progression. In order to fit curves to epidemic data, the sampling interval should be small enough, and the sample size large enough, to ensure sufficient observations for curve fitting. Sampling frequency can be planned with respect to the long-term mean temperature pattern at a site, then modified to take account of actual weather conditions during the experiment. Although short-term fluctuations from the mean should be accommodated, these are usually smaller than the longer-term changes that become important when an epidemic is observed over a long period. For example, S. tritici on wheat may be observed on several leaf layers during the spring in southern England, where a 200 degree-day latent period (with base temperature $-2 \cdot 4^{\circ} \mathrm{C}$ ) typically represents $19-33$ days in early spring (March/April) but only 14-22 days in late spring (May). Use of an appropriate sampling scheme can improve estimation of the thermal time latent period, rate of epidemic progress or level of maximum disease expression. This can be quantified, for a simple case, with a simulation experiment using the standard logistic curve for disease progression. For a single leaf, the probability $p$ of visible lesions at thermal time $T$ after infection can be written as:

$$
p(T)=1 /\{1+b \exp [-r(T-l)]\}
$$

where $l$ is the latent period (thermal time until appearance of first lesions), $r$ is the apparent infection rate and $1 /$ $(1+b)$ represents the probability of visible lesions at $T=l$. To create epidemic progress similar to that typically seen for $S$. tritici, the values used were: $l=200, r=0.05$ and $b=99$, with base temperature $-2 \cdot 4^{\circ} \mathrm{C}$. Taking temperature data from Rothamsted in spring 2000, the binomial distribution was used with $p(T)$ to simulate data for the percentage of leaves observed with visible lesions over thermal time, for infection on 1 March or 1 May with sample sizes of 20 or 50 leaves. Samples were assumed to be taken 200 degree-days after infection, and then at intervals of 7, 5 or 3 days, or 75, 50 or 30 degree-days; 500 simulations were performed for each combination to calculate the estimated infection rate.

The mean temperature during the period 200-400 degree-days after infection was $6 \cdot 1^{\circ} \mathrm{C}$ for infection on 1 March and $11.6^{\circ} \mathrm{C}$ for infection on 1 May. A sample interval of 75 degree-days was therefore equivalent, on average, to 8.8 days in March and 5.4 days in May; 50 degreedays was equivalent to 5.9 days in March and 3.6 days in May; and 30 degree-days was equivalent to 3.5 days in March and $2 \cdot 1$ days in May. The mean estimated infection rate $(r)$ and its standard deviation are shown in Table 2 . The standard deviation indicates variability in the estimated rate across data sets. In all cases the standard deviation of the estimated infection rate decreased as sample frequency increased, and as sample size increased. For sample intervals based on days, the standard deviation was larger when infection took place in May, as fewer samples were taken during the epidemic. Substantial bias in the estimated rate was also present for 7-day samples during May. For sample intervals based on degree-days, there was no difference in the mean or standard deviation of the estimated rates between March and May, but there was bias in the 75 degree-day estimate at both sample sizes, and in the 50 degree-day estimate for a sample size of 20 . Therefore, to determine the estimated infection rate to within $\pm 0 \cdot 02$, sample intervals of 50 degree-days would be required for sample size 50, and intervals of 30 degree-days for sample size 20 for epidemics at any stage in the growing season.

\section{Discussion}

Thermal time calculations are well established as a basic scale for modelling the development of numerous biological

Table 2 Mean value (and standard deviation) of estimated infection rate $(r=0.05)$ from a simulation experiment for different times of infection, sample sizes and sample frequencies; 500 simulations were run for each case

\begin{tabular}{|c|c|c|c|c|c|c|c|}
\hline \multirow{3}{*}{$\begin{array}{l}\text { Infection } \\
\text { date }\end{array}$} & \multirow{3}{*}{$\begin{array}{l}\text { Sample } \\
\text { size }\end{array}$} & \multicolumn{6}{|c|}{ Sample frequency } \\
\hline & & \multicolumn{3}{|c|}{ Days between samples } & \multicolumn{3}{|c|}{ Degree-days between samples } \\
\hline & & 7 & 5 & 3 & 75 & 50 & 30 \\
\hline $1 \mathrm{Mar}$ & 20 & $0.058(0.032)$ & $0.056(0.024)$ & $0.052(0.008)$ & $0.101(0.079)$ & $0.059(0.038)$ & $0.053(0.009)$ \\
\hline 1 May & 20 & $0.133(0.066)$ & $0 \cdot 106(0.086)$ & $0.054(0.019)$ & $0.102(0.080)$ & $0.064(0.051)$ & $0.053(0.010)$ \\
\hline $1 \mathrm{Mar}$ & 50 & $0.052(0.007)$ & $0.052(0.007)$ & $0.051(0.005)$ & $0.063(0.043)$ & $0.052(0.007)$ & $0.051(0.006)$ \\
\hline 1 May & 50 & $0.102(0.067)$ & $0.065(0.048)$ & $0.052(0.007)$ & $0.066(0.048)$ & $0.052(0.007)$ & $0.051(0.005)$ \\
\hline
\end{tabular}


systems. For several plant pathogens, various ontogenetic phases have been reported to be dependent on thermal time accumulation, for example ascospore maturation and release (Spotts \& Cervantes, 1994; Toscano-Underwood et al., 2003); germination (Milholland, 1977); latent period (Fukui et al., 1999; Lovell et al., 2004); and sporulation (Rowe \& Powelson, 1973; Teng \& Close, 1978).

Thermal time is usually calculated using air temperature. While air temperature may be appropriate to many studies of systems such as plant growth and plant pathogens, soil temperature may be more suitable for studies of soilborne and root-infecting pathogens. Lovell et al. (2004) suggested that the observation of a base air temperature below $0^{\circ} \mathrm{C}$ for the latent period of $S$. tritici might be the result of differences between recorded air temperatures and the actual temperatures that the pathogen was exposed to within the host. If it is practically feasible to measure, plant internal temperature may prove more applicable to the modelling of the system under study, as it excludes the effects of the insulating properties of, for example, the epidermis of leaves or bark. Variation in development of ontogenetic phases may well be observed if there are temperature differentials within the host. For example, upper canopy leaves that are subject to high levels of direct radiation may be warmer than lower canopy leaves that receive diffuse radiation. Therefore due consideration should be given to any possible variations between the actual temperature measured and that in which the pathogen resides.

Not all processes are suited for modelling by thermal time. Blunt et al. (1992) found no advantage of using thermal time, as opposed to time from sowing date, when investigating Polymyxa betae, the plasmodiophorid vector of Beet necrotic yellow vein virus. Similarly, when looking at the effect of fluctuating temperatures on Bremia lactucae (downy mildew) in lettuce, Scherm \& Vanbruggen (1994) concluded that variability in the prediction of latent period was greater when measured in thermal time (degree-hours) than when measured in time (days). Ontogenetic phases of pathogen development may also differ in their responses to temperature, so modelling using thermal time must reflect this. For example, $\mathrm{Xu}(1999 \mathrm{~b})$ found that when the latent period for Podosphaera (= Sphaerotheca) pannosa (powdery mildew) in roses was divided into two stages, incubation period and postincubation period, the rate of fungal development had a nonlinear relationship with temperature for incubation, but a linear relationship postincubation.

In general, it appears that insufficient consideration is given to the possible effects of thermal time in epidemiological research. As a consequence, comparisons across experiments are often confounded when experimental sites differ in their temperature profiles and when epidemic processes are measured in terms of days rather than thermal time.

Comparative epidemiology and modelling require that dimensionality and both descriptive and measurement terms are common across studies (Butt \& Royle, 1978). While much attention is given to describing temporal terms such as germination, infection and latent periods, the concept of time itself is generally not discussed. The use of inappropriate time scales may result in comparisons between studies being ineffectual (Figs 3 and 4). Where the response of a biological process to temperature is linear, comparisons between independent studies using a thermal time scale are effective, provided that significant periods above or below the prospective upper and lower threshold temperatures do not occur. However, where temperatures vary significantly, or where the relationship is nonlinear, effective comparisons may be possible only by remodelling the data collectively. An immediate benefit from wider adoption of thermal time scales in plant pathology might be to improve the resolution of datamining methodologies (Pietravalle et al., 2003) that aim to identify important time points and controlling variables for epidemic development. A more far-reaching benefit will be to support the aspiration of integrative bioscience, which will deliver verifiable predictions of the behaviour of complex systems (Crute, 2003).

\section{Acknowledgements}

We would like to thank Ken Scheeringa, state climatologist, Purdue University, IN, USA for advice on and supply of historical meteorological data for Kentland. We are grateful for helpful discussions with Professor C. A. Gilligan, University of Cambridge, UK. Rothamsted Research receives grant-aided support from the Biotechnology and Biological Sciences Research Council.

\section{References}

Aikman DP, Scaife A, 1993. Modelling plant growth under varying environmental conditions in a uniform canopy. Annals of Botany 72, 485-92.

Arnold CY, 1959. The determination and significance of the base temperature in a linear heat unit system. Proceedings of the American Society for Horticultural Science 74, 430-5.

Baker JT, Reddy VR, 2001. Temperature effects on phenological development and yield of muskmelon. Annals of Botany 87, 605-13.

Blunt SJ, Asher MJC, Gilligan CA, 1992. The effect of sowing date on the infection of sugar beet by Polymyxa betae. Plant Pathology 41, 148-53.

Bonhomme R, 2000. Bases and limits to using degree day units. European Journal of Agronomy 13, 1-10.

Brasset PR, Gilligan CA, 1989. Fitting of simple models for field disease progress data for the take-all fungus. Plant Pathology 38, 397-407.

Butt DJ, Royle DJ, 1978. The importance of terms and definitions for a conceptually unified epidemiology. In: Palti J, Kranz J, eds. Comparative Epidemiology: A Tool for Better Disease Management. Wageningen, the Netherlands: Centre for Agricultural Publishing and Documentation, 29-45.

Clarkson JP, Phelps K, Whipps JM, Young CS, Smith JA, Watling M, 2004. Forecasting sclerotinia disease on lettuce: towards developing a prediction model for carpogenic germination of sclerotia. Phytopathology 94, 268-79. 
Crute IR, 2003. Increased crop productivity from renewable inputs - a scientific challenge for the 21 st century. In: Proceedings of the BCPC International Congress - Crop Science and Technology 2003. Alton, UK: British Crop Protection Council, 3-14.

Davies H, 1990. Studies of the Biology and Epidemiology of Rhynchosporium secalis (Leaf Blotch on Barley). London, UK: University of London, PhD thesis.

Fukui R, Fukui H, Alvarez AM, 1999. Effect of temperature on the incubation period and leaf colonisation in bacterial blight of anthurium. Phytopathology 89, 1007-14.

GenStat, 2003. Genstat, 7th edn. GenStat Procedure Library Release PL15. Rothamsted, UK: Lawes Agricultural Trust.

Gladders P, Paveley ND, Barrie IA, Hardwick NV, Hims MJ, Langton S, Taylor MC, 2001. Agronomic and meteorological factors affecting the severity of leaf blotch caused by Mycosphaerella graminicola in commercial wheat crops in England. Annals of Applied Biology 138, 301-11.

Grundy AC, Phelps K, Reader RJ, Burston S, 2000. Modelling the germination of Stellaria media using the concept of hydrothermal time. New Phytologist 148, 433-44.

Lovell DJ, Parker SR, Hunter T, Royle DJ, Coker RR, 1997. Influences of crop growth and canopy structure on the risk of epidemics by Mycosphaerella graminicola (Septoria tritici) in winter wheat. Plant Pathology 46, 126-38.

Lovell DJ, Hunter T, Powers SJ, Parker SR, Van den Bosch F, 2004. Effect of temperature on latent period of septoria leaf blotch on winter wheat under outdoor conditions. Plant Pathology 53, 170-81.

Milholland RD, 1977. Sclerotium germination and histopathology of Monilinia vaccinii-corymbosi from mummified highbush blueberry. Phytopathology 67, 848-54.

Mol L, Huisman OC, Scholte K, Struik PC, 1996. Theoretical approach to the dynamics of the inoculum density of Verticillium dabliae in the soil: first test of a simple model. Plant Pathology 45, 192-204.

Olivier FC, Annandale JG, 1998. Thermal time requirements for the development of green pea (Pisum sativum L.). Field Crops Research 56, 301-7.

Parker SR, Lovell DJ, 2001. Quantifying the benefits of a novel seed treatment for foliar disease control. In: Seed Treatment, Challenges and Opportunities, BCPC Symposium Proceedings No. 76. Alton, UK: British Crop Protection Council, 181-8.

Parton WJ, Logan JA, 1981. A model for diurnal variation in soil and air-temperature. Agricultural Meteorology 23, 20516.

Pfender WF, 2003. Prediction of stem rust infection favourability, by means of degree-hour wetness duration, for perennial ryegrass seed crops. Phytopathology 93, 467-77.

Pietravalle S, Shaw MW, Parker SR, van den Bosch F, 2003. Modeling of relationships between weather and winter wheat diseases: a critical approach. Phytopathology 93, 1329-39.

Powers SJ, Brain P, Barlow PW, 2003. First-order differential equation models with estimable parameters as functions of environmental variables and their application to a study a vascular development in young hybrid aspen stems. Journal of Theoretical Biology 222, 219-32.
Purcell LC, 2003. Comparison of thermal units derived from daily and hourly temperatures. Crop Science 43, 1874-9.

Reader RJ, Phelps K, 1991. Modelling the development of temperature-dependent processes. GenStat Newsletter 28, 27-32.

Réaumur RA, 1735. Observations du thermomètre faites pendant l'année MDCCXXXV comparées à celles qui ont été faites sous la ligne à l'Isle-de-France, à Alger et en quelquesunes de nos Isles de l'Amérique. Mémoires de l'Académie Royal des Sciences, 545-76.

Reicosky DC, Winkelman LJ, Baker JM, Baker DG, 1989. Accuracy of hourly air temperatures calculated from daily minima and maxima. Agricultural and Forest Meteorology 46, 193-209.

Rowe RC, Powelson RL, 1973. Epidemiology of Cercosporella footrot of wheat: spore production. Phytopathology 63, 9814.

Scherm H, Vanbruggen AHC, 1994. Effects of fluctuating temperatures on the latent period of lettuce downy mildew (Bremia lactucae). Phytopathology 84, 853-9.

Scherm H, Savelle AT, Pusey LP, 2001. Interactions between chill-hours and degree-days affect carpogenic germination in Monilinia vaccinii-corymbosi. Phytopathology 91, 77-83.

Schoeny A, Lucas P, 1999. Modeling of take-all epidemics to evaluate the efficacy of a new seed-treatment fungicide on wheat. Phytopathology 89, 954-61.

Sharpe PJH, DeMichele DW, 1977. Reaction kinetics of poikilotherm development. Journal of Theoretical Biology 64, 649-70.

Spotts RA, Cervantes LA, 1994. Factors affecting maturation and release of ascospores of Venturia pirina in Oregon. Phytopathology 88, 260-4.

Teng PS, Close RC, 1978. Effect of temperature and uredinium density on urediniospore production, latent period and infectious period of Puccinia hordei Otth. New Zealand Journal of Agricultural Research 21, 287-96.

Toscano-Underwood C, Huang YJ, Fitt BDL, Hall AM, 2003. Effects of temperature on maturation of pseudothecia of Leptosphaeria maculans and L. biglobosa on oilseed rape stem debris. Plant Pathology 52, 726-36.

Tyldesley JB, 1978. A method of evaluating the effect of temperature on an organism when the response is non-linear. Agricultural Meteorology 19, 137-53.

Vanderplank JE, 1963. Plant Diseases: Epidemics and Control. New York, USA: Academic Press.

Wurr DCE, Fellows JR, Phelps K, 2002. Crop scheduling and prediction: principles and opportunities with field vegetables. Advances in Agronomy 76, 201-34.

Xu XM, 1999a. Modelling and forecasting epidemics of apple powdery mildew (Podosphaera leucotricha). Plant Pathology $48,462-71$.

Xu XM, 1999b. Effects of temperature on the latent period of the rose powdery mildew pathogen, Sphaerotheca pannosa. Plant Pathology 48, 662-7.

Yin XY, Kropff MJ, McLaren G, Visperas RM, 1995. A nonlinear model for crop development as a function of temperature. Agricultural and Forest Meteorology 77, 1-16. 